\title{
Ibizan Hound
}

National Cancer Institute

\section{Source}

National Cancer Institute. Ibizan Hound. NCI Thesaurus. Code C53915.

The Ibizan Hound is an agile, deer-like, athletic hound that has a long, arched neck, long wedge-shaped head, and very large, triangular ears which stand up when the dog is alert. The rose or flesh-colored nose has a slightly convex shape called "Roman nose." The Ibizan Hound is "hare-footed," with long toes. There are three varieties of Ibizan: smooth-haired, long-haired, and wire-haired. Colors are white and red, white and tan, or solid white or red. Height: 22-29 inches (56-74 cm.) Weight: 42-55 pounds (19-25 kg.) 